\title{
A THEORETICAL APPROACH FOR ASSESSING SUSTAINABILITY IN HOUSING ENVIRONMENTS
}

\section{Beser Oktay Vehbi, Ercan Hoskara \& Sebnem Önal Hoskara}

\begin{abstract}
This study' seeks to identify and propose a model for measuring and assessing the level of sustainability in housing environments based on a range of indicators. With this intention, the article is composed of four main parts. In the first part, the relationship between sustainability and housing is presented based on previous research; in the second part, a theoretical framework is put forward for sustainable housing. Then in the third part, sustainability indicators are discussed thoroughly within the context of indicator frameworks. In this section, the development, selection and measuring processes of indicators are also introduced. Finally in the fourth part, the model for measuring and assessing the level of sustainability in housing environments is presented. It is believed that this model will be used as a tool in the decision-making processes for the future development of existing housing settlements and their environments.
\end{abstract}

Keywords: Sustainable Housing, Sustainability Indicators, Sustainable Indicator Frameworks, Housing Indicators.

\section{INTRODUCTION}

There are two broad concepts to be discussed in this paper as a part of its main aim and objective. These are: sustainability and housing. It is believed that these broad concepts relate to each other in everyday life. These concepts will be briefly discussed in the following text by researching the appropriate literature, which will serve as the main aim of the paper.

The broad concept of sustainable development was discussed in the early 1980's, World Conservation Strategy (IUCN, 1980), but was placed firmly on the international agenda with the World Commission on Environment and Developments (WCED) publication of Our Common Future (Brundtland Report) in 1987, as well as with the landmark World Bank paper Environment, Growth and Development in the same year.

There are many definitions of sustainability and sustainable development. The most common and well- known definition is that put forward by the Brundtland Report. According to the Brundtland report: "sustainable development is development that meets the needs of the present without com- promising the ability of future generations to meet their own needs" (WCED, 1987). This definition coins the essential components of the concept in simple terms: that of equity within and between generations, and that our ability to meet needs is bounded by the limitations of the earth's resources. The concept of sustainable development was initially debated and interpreted in terms of the limitations of the earth to accommodate all human activities. For example, it is equated with a commitment to living within the earth's limits in respect of the 'carrying capacity' of the biosphere, defined as the optimal animal population that a given ecosystem or environment can sustain, and collapse will occur if that capacity is exceeded (Healey and Shaw, 1993; Jacobs, 1999). Another definition reflects the managing of resources in such a way that enables the meeting of aspirations of society over a considerable period of time. Thus, sustainability refers to the ability of the natural environment, or the ecosystem, to accommodate human activities, especially those constituting economic development, in the long term.

Sustainability has three main dimensions: being ecological/environmental, economic and socio-cultural sustainability. The linkages between

\footnotetext{
1 The study presented in this article is an extended version of a paper presented at the ENHR 2007 Conference on Sustainable Urban Areas in Rotterdam 25-28 June 2007. (Ref: Oktay, B., Hoskara, E. and Hoskara, S., 2007, "Assessing the Level of Sustainability in Housing Environments: A Theoretical Approach", ENHR 2007 Conference on Sustainable Urban Areas, 25-28 June 2007, Rotterdam.)
} 
these different dimensions of sustainability should be fully taken into account, and they should not be isolated from one another (Khan, 1995; Goodland and Daly, 1996; Mitlin and Satterthwaite, 1996, Hart, 1999; Williams, et al, 2000; Chiv, 2003).

The second concept of this paper - housing, represents the physical manifestation of investment in a community, and directly relates to a primary concern of municipalities, that of land use and development, and provides a link between physical development and social and economic outcomes. Housing, therefore, appears to be a reasonable and potentially powerful medium for monitoring the social, physical, environmental and economic characteristics of community.

Moser (1987) describes housing as the constructed physical fabric of the house and the land on which it is built. Yet, housing is only part of the larger residential environment. Specific components of the residential environment are seen as those parts of the individual and community identity that impact on health and well-being. These components include: the living unit and the division of space within the unit, hidden space within the building, indoor and outdoor recreational areas, sanitary facilities, water supply, protection from weather, heat and noise insulation, neighborhood circulation patterns, and proximity to sources of noise and fumes (Kasl, 1979; Burden, 1979).

It is with great caution that the concept of 'sustainability' is applied to housing. V. Cammalleri \& J. Nicell state that: "the notion of sustainable housing is often associated with such technical considerations as environmentally-safe materials and energy-efficient envelope design" (Cammalleri and Nicell, 1997: 31-35), and accordingly, we would still like to propose that a sound housing policy and its implementation could achieve significant socioeconomic, environmental and physical sustainability.

In his essay: "Towards a Sustainable Housing Development" Dilip da Cunha - states that: "Housing, because of its ability, as a total entity, to satisfy all the levels of need - spiritual, cultural, economic and physical is in a unique position to be the leading sector, showing the way towards more holistic policies and sustainable development" (Da Cunha, 1988). Furthermore, the Brundtland Report recommends that: "the principle of sustainable development must be built into all activities" (WCED, 1987).
According to Agenda 21, "access to safe and healthy shelter is essential to a person's physical, psychological, social and economic well-being and should be a fundamental part of national and international action (UNSD, 1992)". This statement also describes the importance of housing - as shelter, in sustainable development.

Also the Global Report on Human Settlements, one of the publications of The Habitat Conference points out that: "the central importance of housing to everyone's quality of life and health is often forgotten". Decent housing contributes much to personal health and well-being, confidence and security; the ways in which housing is produced and exchanged have an impact over developmental goals such as equity and poverty eradication; house construction and location can influence environmental sustainability and the mitigation of natural disasters, and the design of dwellings both reflects and protects something important about culture and religious beliefs."

From these brief discussions above, it can be argued that housing is on the cutting edge of sustainability. Thus, housing environments have a crucial role to play in the sustainable development of cities, and, accordingly, they are an important component of the built environment, there is a need to have socially and environmentally sustainable housing environments in order to achieve attractive, sustainable and healthy living areas.

The multi-faceted scope of both the sustainable development concept and of housing by its nature, and the fact that housing is integral to urban sustainability, have underpinned the validity and the need to evaluate housing development and chart its future development from the perspective of sustainable development. The next section, therefore, presents a sustainable development framework for housing.

\section{A SUSTAINABLE DEVELOPMENT FRAMEWORK FOR HOUSING}

The relationship between sustainability and housing is in two-ways. Incorporating principles of sustainability into housing development, maintenance and refurbishment will not only make a significant contribution to the achievement of general sustainability objectives, but it will also provide important advances in the quality, durability and cost effec- 
tiveness of our housing developments.

There is a need for a change in culture with regard to housing development, which places sustainability in the centre stage. This should include the developers (be they housing associations or private companies), builders and land use planners and also the tenants and owners. Sustainability objectives in housing will be achieved only if they are taken into account at all stages of the design process - from the initial construction - to long term use and the eventual disposal and recycling. The raising of awareness at all stages is important for all those involved.

The sustainability of housing environments has three inter-related dimensions - environmental, socio - cultural and economic, as with sustainable development. The primary concern of sustainable housing, therefore, should be to meet the accommodation needs of the citizens; the housing environment concerned has to be safeguarded from deteriorating to the extent that it diminishes the ability of future generations to meet their housing needs. Furthermore, sustainable housing should not be merely about meeting basic needs, but it should also improve livability and quality of life in terms of the economic, social and cultural aspects. Accordingly, there are many important factors that make housing important for achieving sustainable development

(http://www.housingcorp.gov.uk/server/show/nav. 1408):

- Housing is a basic human need - its quality, cost and availability are crucial to the quality of life of individuals.

-Well-designed and well- maintained housing helps to support a sense of community, just as run-down neglected housing will tend to erode it.

- The location, planning, layout and design of housing make an important contribution to community spirit and identity, which are significant components of the social dimension of sustainable development.

- There is an inter-relationship between housing, health and well-being, educational access and attainment, and access to employment.

- The position of houses, the materials of which they are made, the uses their occupants make of resources such as energy and water, and the availability of public transport/alternative forms of transport all have major environmental impli- cations.

- Many residents of housing associations suffer from social exclusion and can be benefit dependent. They are a key target group for many government policies including social inclusion, eliminating child poverty, decent homes, job generation and employment addressing fuel poverty, health and education improvement.

- 70 of the 147 national sustainable development indicators, and many of the regional and local indicators, can be linked to housing and community issues.

With these discussions in mind, housing environments can be regarded as "sustainable" if they are planned and designed in such a way that:

- The location of housing should ideally be in close proximity to the residents place of work, services and public transport.

- The layout of the housing development is in compact urban form - providing an open space network, serving a number of inter-related purposes concerning managing pollution, wildlife, energy, water, sewage, and green space.

- Housing development is structured around energy-efficient movement networks in which the level of accessibility is maximized, and travel and car dependency is minimized, and, where necessary, can be achieved by walking, cycling or using public transport, so that travel choice for all groups in society is increased, and all parts of a development are provided with good access to public transport.

- The design of housing is energy efficient; thus, where there is a strong energy strategy, which relates to reducing heat loss, maximizing solar gain and solar energy use, combined heat and power potential, embodied energy.

- The housing area develops a water strategy by relying on end-of-pipe off-site solutions; minimizing consumption; encouraging on-site infiltration and waste treatment.

- The level of pollution and waste is minimized, and where a degree of pollution is unavoidable, the place should as far as possible be selfcleansing.

- The characteristics of vitality, variety and legibility in the housing environment are high in quality in order to give the users / residents a sense of place - with the objective of reducing 
any sense of "placelessness".

- The quality of local environment / life is improved by creating an attractive, safe and well-supervised urban environment with social stability and a sense of community.

Thus, the above listed features can be regarded as the general main features of sustainable housing.

The above paragraphs described how housing can contribute to the achievement of sustainable development objectives. This is a two-way process because the most cost-effective way to develop and maintain a high quality housing stock in the long term is to incorporate principles of sustainability into all parts of the housing development process. Since new buildings comprise only a small fraction of the existing stock, it is also important that refurbishment incorporates sustainability principles.

While planning and designing sustainable housing environments, in order to provide the existing housing areas with a healthy and sustainable future, there is also a need to measure and assess the level of sustainability in those areas so that future planning decisions - such as maintenance, refurbishment, revitalization etc. can be taken accordingly. Thus, considering the main aim of this paper, that is to identify a model for assessing the level of sustainability in housing environments, the following lines will first present detailed information on sustainability indicators, which are essential, to set up a measuring model. The paper will then seek to identify a method to develop and select the sustainable housing indicators, within an indicator framework.

\section{SUSTAINABILITY INDICATORS: FRAMEWORKS, SELECTION AND MEASUREMENT}

Generally speaking, Adriaanse (1993) defines an indicator as a quantitative model and a form of information that makes a certain phenomenon perceptible that is not immediately detectable. Indicators, therefore, provide a simpler and more readily understandable form of information than complex statistics or complex phenomena. The three main functions of indicators are: quantification, simplification and communication. Indicators also help to follow the change of phenomena in time scale and the development of phenomena in relation to the stated objects. One of the other important functions of an indicator with reference to decision-making is its potential to show the trend, i.e. the course of development, at an early stage. In order to work with indicators, one needs data, which comes from a monitoring process. Therefore, indicators should be objective and the results should be repeatable. In many cases, indicators should also be internationally comparable, although those were mainly used nationally. The main risk with regard to indicators is the concern over simplification and the loss of important information.

Agenda 21, chapter 40 states that: "indicators of sustainable development need to be developed to provide solid bases for decision making at all levels, and to contribute to a self-regulating sustainability of integrated environmental and development systems (CRISP, 2001)."

There are numerous studies on indicators, in the literature, in general, and sustainability indicators in particular. For example, two scholars, Gilbert and Feenstra (1992) have, on the basis of the literature, identified four desirable features of indicators:

- The indicator must be representative of the system chosen and must have a scientific basis.

- Indicators must be quantifiable.

- Part of the cause-effect chain should be clearly represented by the indicator.

- The indicator should offer implications for policy.

According to some other scholars (Atkisson, et al. 1997; Maclaren, 1996; Hart, 1999), good sustainability indicators should be relevant, valid, consistent, reliable, comparable, measurable and comprehensive.

A more detailed study is offered by MacLaren (1996) who distinguished urban sustainability indicators from simple environmental, economic, and social indicators by the fact that they do not only integrate, but are also forward looking, distributional, and have the benefit of input from multiple stakeholders. According to him, evidence of progress on urban sustainability is important for justifying past expenditures on sustainability initiatives and for building support in respect of new initiatives. As Macleren (1996) stated, "sustainability indicators are usually site specific, and indicators designed to measure progress towards sustainabil- 
ity in one urban area may not be appropriate for another city". Thus, in order to be useful, indicators must verify (a) whether sustainability in settlements is improving or deteriorating in relation to certain sustainability criteria or desirable targets, and (b) how these trends are linked to trends in spatial structure, urban organization and lifestyles.

Sustainability indicators in respect of a community are used to give an overall indication of that community's economic, environmental and social conditions in terms of its sustainability - taken as a whole they describe whether these systems are likely to be maintained over the longer term or if they will over time gradually degrade. Since we cannot, at this time, actually assess when a community has become truly "sustainable", sustainability indicators cannot inform us about how far we still have to go, but they can let us know if we are moving in the right direction.

In order to develop effective indicators, which address the issue of sustainability and which improve upon those used in the past, it is important to recognize factors that contribute to successful indicator packages. There are four major components to sustainability indicators that distinguish them from other types of indicators. Sustainability indicators should: highlight linkages; be forwardlooking; examine distributional equity; and, be developed with diverse community input (Macleren, 1996; Hart, 1999; Oktay, 2005).

Building upon the definition of an indicator, a sustainability indicator considers measurements and trends that link or combine all three dimensions of a sustainable or healthy community: economic, environmental, and social factors. When developing sustainable development indicators, it is important to address the challenge of fully integrating the social, economic, environmental and institutional aspects of development. In this respect, sustainable development indicators are different from sectoral indicators such as geo-indicators, bio-indicators, social and economic indicators. Sustainable development indicators must be capable of capturing the interrelationships between the social, economic and environmental dimensions of development. This is not an easy task as the interrelationships between the environment and economics, or social change and the environment, have not been fully explored and understood. Social, economic and environmental indicators have mostly been used independently from each other since their concep- tion. The scientific community requires carrying out much more research and work in order to develop indicators that describe the interlinkages between the different dimensions of development.

According to the Planning Authority (1997), sustainability indicators have three central functions: to simplify the main concepts related to sustainable development; to quantify and measure aspects of sustainable development; and, to communicate them to the public and policy makers. Similarly, as Oktay (2005 stated, relevant and measurable indicators can be used to measure the current level of sustainability and at the same time they can give information about how the level of sustainability can be increased in an urban area.

Sustainability indicators are becoming increasingly important as tools for examining sustainable development in urban settlements. Many initiatives have been taken to develop sustainability indicators, and several international organisations have created specific programmes to develop and harmonise urban sustainability indicators. These include the UN Centre for Human Settlements (UNCHS, 1996), Agenda 21 of the United Nations Conference on Environment and Development (UNCD), European Union, the UN Commission on Sustainable Development, the World Bank (1999), the Organisation for Economic Co-operation and Development (OECD, 1993), The European Environment Agency (EEA, 1996) and the World Health Organisation). In the following text, indicators have been grouped in their different categories or frameworks and an attempt has been made to provide a summarised description of each category or framework based on the ISO 14031 terminology.

\section{INDICATOR FRAMEWORKS AND TYPES OF INDICATORS}

An indicator framework outlines the typology of indicators. There are three different indicator frameworks described by different organisations.

The first one is, as introduced by Organization for Economic Co-operation and Development (OECD), Pressure - State - Response (PSR) model, which provides a classification of indicators of environmental pressures, environmental conditions and societal responses. According to the PSR model, indicators of environmental pressures 
describe pressures resulting from human activities, which are exerted on the environment, including natural resources; indicators of environmental conditions relate to the quality of the environment and the quality of the natural resources; indicators of societal responses show the extent to which society responds to environmental concerns (OECD, 1993).

The second indicator framework has been drawn up by UN Commission on Sustainable Development (UNCSD)'s which is named as a Driving Force - State- Response (DSR) framework. The replacement of the term "pressure" in the PSR framework by the term "driving force" was motivated by the desire to include economic, social and institutional aspects of sustainable development. This adjustment was deemed necessary when one shifts from a consideration of environmental indicators to these indicators plus the state of the human subsystem (Gallopín, 1997: 22). The extension of the focus to all aspects of sustainable development (social, economic, environmental and institutional) is argued to be "particularly important for developing countries...for whom an equal balance between the developmental and environmental aspects of sustainable development is important in order to ensure future sustainable growth patterns" (Gallopín , 1997: 49).

Another aspect of the DSR framework, which separates it from its predecessor, is that there is no assumption of causality between indicators in each of the categories. "The term 'driving force' indicates... an impact on sustainable development. This impact can be both positive and negative, which is not the case for the pressure category used by the OECD. Driving force indicators represent human activities, processes and patterns that have an impact on sustainable development" (Mortensen, 1997: 48).

The third framework is the European Environment Agency (EEA)'s Driving Force Pressure - State - Impact - Response (DPSIR) typology in which the driving force indicators describes social, demographic and economic development in societies and the corresponding changes in life styles, levels of consumption and production patterns. The DPSIR model "....has been adopted as the most appropriate way to structure environmental information by most member states of the European Union..."(European Community, 2000). In this framework:
- Driving forces represent basic sectoral trends in energy generation, transport, industry, agriculture, tourism, etc.

- The word pressure refers to human activities directly affecting the environment such as the production of carbon dioxide.

- The word state refers to observable changes in the environment, such as global warming.

- The word impact represents the effects, which a changed environment has as in the case of e.g. floods or other naturally occurring disasters.

- The word response refers to the response of society in respect of resolving environmental problems by introducing, for example, the concept of energy taxes.

In the context of the DPSIR model, Eurostat focuses on response, driving forces and pressure indicators, whilst state and impact indicators are mainly the domain of the EEA (Hoskara, 2007).

Following the main aim of this paper, the DSR indicator framework will be taken as a basis for grouping the housing indicators in the selection process, since this framework covers all three dimensions of sustainability simultaneously and in a more practical way than the other frameworks. However, it should be kept in mind that, the most comprehensive framework - DPSIR or the other one - PSR may also be preferable if the time allows and if they are found to be more useful for the purpose.

\section{FORMULATION, SELECTION AND MEASUREMENT OF SUSTAINABILITY INDICATORS}

Before selecting the indicators, as community sustainability needs to be defined by the community itself, it is essential that the same community also determines what measures are useful in measuring the progress toward its definition of sustainability. Therefore, broad community participation with representation from diverse groups is necessary to develop good community sustainability indicators.

Because they are multi-sectoral and inter-disciplinary, indicators of sustainability are always produced by relatively large teams of people, whose work is facilitated by a smaller coordinating group. Most often, public involvements is also used to help define a sustainability vision, set goals, and identify 


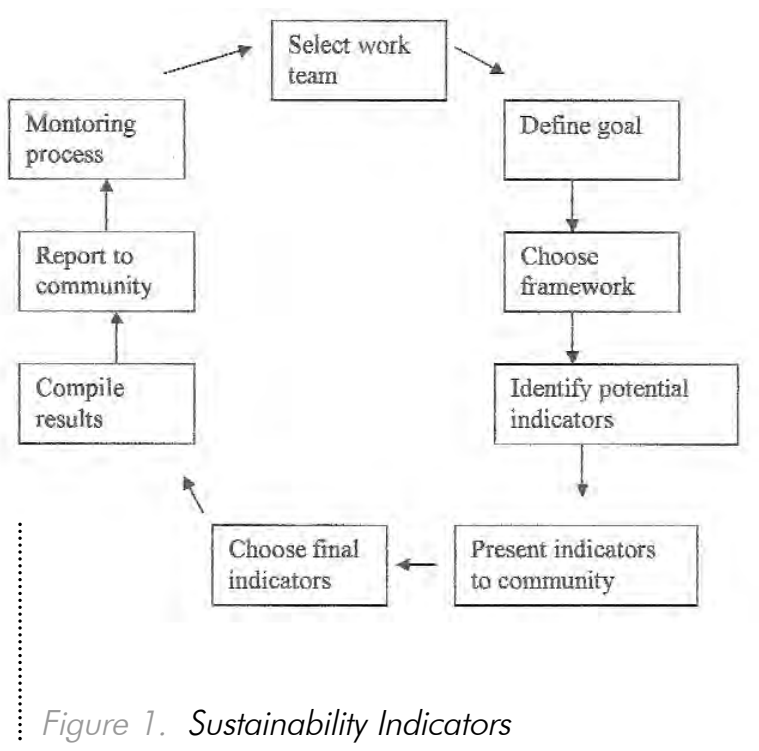

potential measures. To put it more simply, the community should choose its list of sustainability indicators as it moves towards smart growth. Its list should reflect where the community wishes to go. It should be a participatory process, as detailed in other parts of this paper. The final selection of indicators will depend upon the goals of the community, data accessibility, and resource availability. However, one process that a community might consider in developing its list of sustainability indicators is set out in Figure 1.

For this paper, two approaches by two different authors - Vemuri (1978), which was then later adopted by Rasmussen and Dalsgaard (1994), and Gordon Mitchell et. al (1995)- are adapted together and proposed as a new method for the formulation or selection of sustainability indicators. The first method that was formulated by Vemuri in 1978 and later adopted by Rasmussen and Dalsgaard (1994) helps to provide a context for the indicators with which to gauge success in achieving community sustainability goals. However, only indicators that are directly related to the goal are used. Again, complex issues that combine environmental, economic, and social factors may be missed.

This method starts with the goal of the decision-maker, but for measuring how well this goal is achieved, it is needed to break down the goal into a number of objectives, central to fulfilling the goal. These objectives $(B 1, B 2, \ldots$ in Figure 1) can further be divided into causing factors $(C 1, C 2, \ldots)$ and finally into indicators (D1, D2,...), which can be measured and are quantifiable, as shown schematically in Figure 2.

$-32$

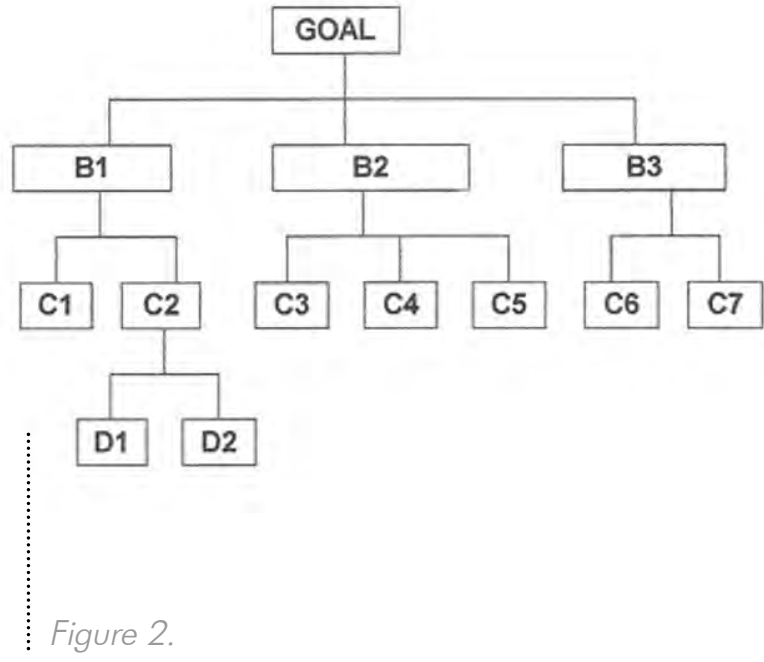

The second and similar method is largely based upon Gordon Mitchell's (1996) work in the United Kingdom. In a broad sense, the community begins with the concept "sustainability", identifies its component parts (issues), selects indicators to accurately reflect the presence or absence of that dimension, and then evaluates the final indicator set.

After completing the evaluation process of the relevant and good indicators for the community and/or housing area, a testing or it is necessary to determine the measuring method of the selected sustainability indicators.

During this research, many methods of measuring sustainability have been considered. Specialists in the area of sustainable development have developed many different ways in which to test sustainability (Randall, 2004; Cunningham et al. 2004). However, to date, no single method has been accepted, so the only way forward is to keep developing ideas, refining them. Literature review shows that (Randall, 2004; Cunningham et al. 2004; Breheny, 1993), the measuring or testing sustainability is carried out focusing on the comparisons between urban areas or on the same area over different periods of time.

Five categories of methods have been developed to be used in the assessment and analysis of environmental effects and sustainability. These methods are: checklists, scaling and weighting techniques, overlays, matrices, networks. For this paper, the scaling technique was selected for use in measuring sustainability. The scaling of effects addresses issues of magnitude and is based on a numerical system in which the highest number represents a very good effect and the lowest number 
represents a very adverse effect. The mid-point would be an average effect, or a neutral one. For example, using a scale of 1 to 5 in a sustainability study, the following definitions could be applied to qualitative assessments of some activity or process:

- 1 - unsustainable in all respects

- 2 - approaching unsustainable conditions

- 3 - partially sustainable

- 4 - sustainable in most aspects

- 5 - highly sustainable

This scaling method can be used alone to determine some composite score for magnitude or it can be combined with a weighting scheme to incorporate considerations of importance or significance. After describing and explaining the necessities of formulating sustainability indicators, their selection and measuring methods for assessing the level of sustainability in general, this paper will now continve to set out a proposal of a model for assessing the level of sustainability in housing areas.

\section{THE MODEL FOR ASSESSING THE LEVEL OF SUSTAINABILITY IN HOUSING ENVIRONMENTS}

Based on the relationship between sustainability and housing as discussed previously, in order to test or asses the level of sustainability of housing environments, indicators of sustainable housing need to be determined. In some literature, there are some studies, which introduce housing related indicators in general terms. Some of these indicators taken from the reviewed international and national policy documents are:

- floor area per person; population of urban, formal and informal settlements;

- distance traveled per capita by which mode of transport and intensity of energy use (as introduced by UNCDS, 1996) or;

- availability of dwellings, amenities, size of dwelling, state of repair of dwelling, tenure status, type of accommodation, affordability of housing, amenities in residential areas,

- environmental quality of residential area, public safety,

- subjective evaluation of housing, subjective evaluation of the residential area, subjective safety in the residential area, regional disparities in housing conditions,
- income related inequality of housing conditions, homelessness, poor housing conditions, area used for settlement, energy consumption, preferences related to dwelling, preferences related to residential area (as have been introduced by European System of Social IndicatorsESSI) (Berger-Schmitt, 2001; Berger-Schmitt and Noll, 2000); or

- some others - gathered from other sources such as satisfaction with housing availability, affordability and standards; accessibility of council housing; urbanized or artificially modeled land (size of artificially modeled area as a percentage of the total municipal area);

- derelict or contaminated land (total square area) ); intensity of use (number of inhabitants per $\mathrm{km} 2$ of the area classified as 'urbanized land'; new development/new buildings on Greenfield sites and new buildings on contaminated or derelict area (brownfield) compared to total area (\%);

- restoration of urban areas (renovation and conversion of derelict buildings - total number, total square area of each floor); redevelopment of derelict areas for new uses, including public open spaces (area in m2); cleansing of contaminated land (area in m2); local mobility and passenger transportation; noise pollution; re-usability and regeneration of derelict or disadvantaged areas;

- avoidance urban sprawl, achieving appropriate urban densities and prioritizing brownfield site over greenfield site development; ensure mixed use of buildings and developments, with a good balance of jobs,

- housing and services giving priority to residential use in city centres;

- ensuring appropriate conservation, renovation and use/re-use of our urban cultural heritage;

- apply requirements for sustainable design and construction and promote high quality architecture and building technologies.

These indicators have multi-dimensional, linking, in other words each of them covers social, economic and environmental dimensions.

In 2005 the EU produced indicators based on its sustainable development strategy. The housing related indicators introduced by the EU are: adequacy of housing conditions or access to 


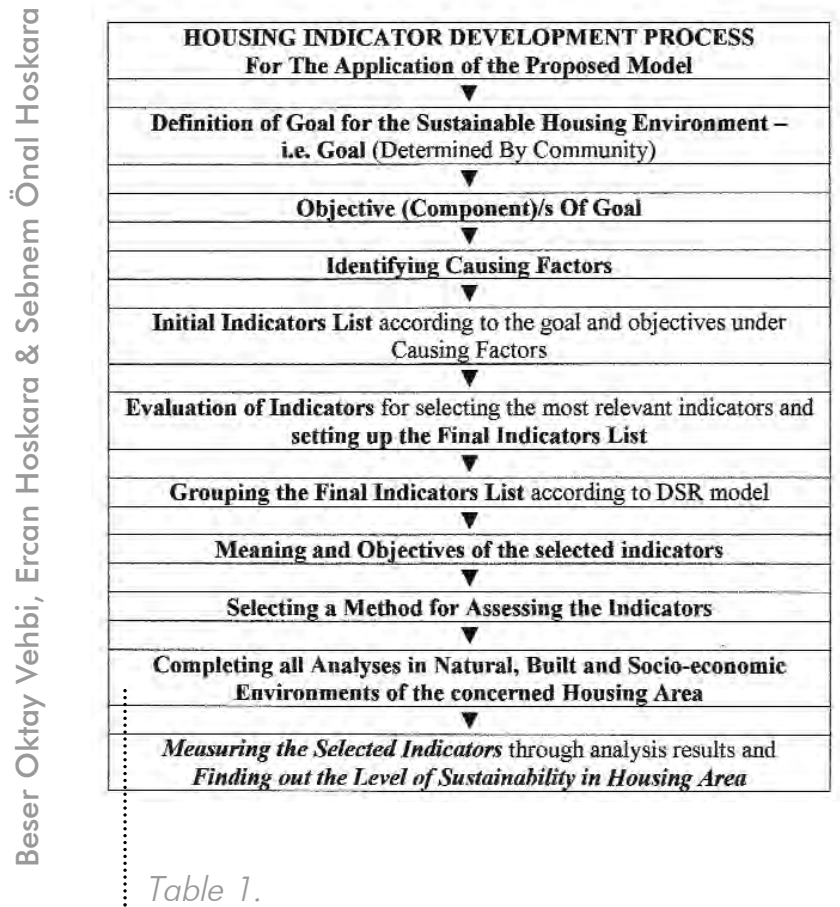

decent housing conditions living in households considering they suffer from noise and from pollution; energy consumption by sector (includes households and services); land use change by category; built up area as \% of total land area; car share of inland passenger transport; access to public transport. Most of the indicators are related to the environmental dimension so the multi-dimensional characteristics of the indicators are missing from this list.

These housing related indicators lists, which have been produced, developed and proposed at international levels by some international organizations (such as Habitat Agenda, the UNCHS Indicators Programme, 1996; CEROI initiative Cities Environmental Reporting on the Internet; neighborhood sustainability guide book, 1999; Sustainable Seattle, 1995; OECD Urban Indicators, 1997; etc.) might or might not be relevant for all areas - in all countries and/or cities. As Macleren (1996) states, each community should determine its own sustainability definition before determining the most appropriate and relevant sustainability indicators for their community. Thus, for each study area in which the level of sustainability needs to be assessed and measured, it is necessary to develop and select a number of "site-specific housing related indicators.

This paper proposes a model for assessing the level of sustainability in housing environments which also covers a methodology for selecting $-34$ these site-specific indicators. This model is described in its various stages in the following text and it is also summarized in Table 1. Thus, for the selection of relevant housing indicators, the indicator development process is proposed to make up from the combination of two different methods as stated earlier. . One of the methods belongs to Gordon Mitchells (1996) and the second one is Vemuri's method (1978), which was adopted by Rasmussen and Dalsgaard (1994). Based on this adaptation, the housing related indicators selection process for the principal task of measurement and establishing the level of sustainability in housing environments, in this paper, consists of eleven steps (see Table 1):

1. Identification of the community's goal for a sustainable housing environment: As explained before, the best indicators relate to a defined vision or goal, and support us to determine how close we come to meeting that goal.

2. Identification of objectives (components) of the goal: Depending on the defined goal for a specific case area, the objectives are needed to achieve this goal.

3. Determining the causing factors of each objective depending on the characteristics of a specific case study area.

4. Construction of indicators under the determined causing factors. In other words, grouping of all indicators separately under three sub-systems (economic, environmental, and social) according to common issues, i.e. the causing factors.

5. Having the initial indicators list based on goals and objectives. (This list generally consists of indicators, which may still not be relevant for a case study area. In order to understand their relevance the next step should be completed.)

6. Evaluation of initial indicators list in order to find the most relevant indicators for a case study area, using evaluation cards and setting up the final indicator list.

7. Grouping the final indicator list based on the Driving Force - State - Response (DSR) framework / model, in order to classify them according to their impact on the area.

8. Identification of meaning, required data and objectives of the selected indicators.

9. Selecting a method for measuring the indicators (Scaling from 1 to 5 is proposed).

10. Analyzing the natural, built and socioeconomic environment of housing areas by 
employing multi-dimensional analyses techniques.

11. Measuring the selected indicators according to analysis results and statistical information (census, etc.) and identifying the level of sustainability in housing areas.

\section{CONCLUDING REMARKS}

Housing as a basic human need and housing and/or residential environments as one of the basic elements of the urban pattern play a crucial role in the sustainability of human settlements. Having identified the key issues of sustainable housing being compact in urban form with an appropriate energy-efficient open space network, having a strong energy and water strategy through which consumption is minimized, heat-loss, levels of pollution and waste are reduced, solar energy is used and any sense of 'placeless-ness' is reduced, - this paper has set out a theoretical framework based on the sustainable housing concept. The paper has used this framework to propose a model for assessing the level of sustainability in housing environments. Depending on this aim and the model, a method for developing and selecting site-specific housing related indicators according to different indicator frameworks, are explained.

In setting out to test the applicability of this approach in assessing the sustainability of housing environments in any urban area, it is stated that each case study site needs to have a different set of indicators according to the differences in their geographic, economic, social and environmental structures. In other words, indicators may vary in their relevance according to the local environment and the final purpose of their measurement and monitoring (and the practicality of this measurement). It is also important to select indicators with the participation of and the consultation with the community in order to obtain valid and realistic indicators of their success and sustainability. The indicators selection process should be characterized by loops and feedback between the various people involved (most importantly, by the various project teams and the inhabitants of the study areas).

During the application of the model to a case study area, the community participation process and the availability of data for measuring some of the selected indicators are some of the obstacles that can occur. In respect of the issue of participation, and the fact that this will involve many people from different disciplines and class, the list of the indicators determined by those people cannot all be relevant or acceptable to all. Yet, at the end of the participation process, it should not be forgotten that the indicators should be beneficial and in line with the defined (sustainability) goal.

It is believed that the proposed model can be applicable in any housing area and it can be used as a tool in the decision-making process for the future development of existing housing environments. While doing so, one of the indicator frameworks can be used in the grouping of the housing indicators in the selection process, although for practical purposes, this paper proposes to use the DSR framework.

\section{REFERENCES}

ADRIAANSE A. 1993. Environmental Policy Performance Indicators, Ministry of Housing, Physical Planning and the Environment, The Hague.

ATKISSON A. et al. 1997. Community Indicators Handbook, Redefining Progress, Seattle.

BERGER-SCHMITT, R. 2001. Dimensions, Indicators and Time Series in a European System of Social Indicators by Example, EuReporting Working Paper No. 16, ZUMA, Mannheim.

BERGER-SCHMITT R. and NOLL H. 2000. Conceptual Framework and Structure of a European System of Social Indicators, EuReporting Working Paper No. 9, ZUMA, Mannheim.

BREHENY M, GENT, T. \& LOCK, D. 1993. Alternative Development Patterns: New Settlements, HMSO, London.

BURDEN R. 1979. The forgotten environment, in, Hinkle, L., E., and Loring, W. (eds.) The Effect of Man-made Environment on Health and Behaviour, DHEW Publications, Atlanta,

Georgia.

CAMMALLERI V. \& NICELL J. 1997. Energy Efficiency and Waste Reduction in Construction of Affordable Homes, Open House International, Vol. 22, No 4, p31-p35.

CHIU, R.L.H. 2003. "Sustainable development, social sustainability and housing development: the experience of Hong Kong" Forrest, R. and Lee, J. (eds.) Housing and Social Change: West meets East, London: Routledge.

CUNNINGHAM B., BATTERSBY N., WEHRMEYER W., and FOTHERGILL C. 2004. A Sustainability Assessment of a Biolubricant, Journal of Industrial Ecology 7, 3-4, p.179-192.

CONSTRUCTION and CITY RELATED SUSTAINABILITY INDICATORS (CRISP) 2001. Online. Available:

cic.vtt.fi/eco/crisp/state-of-the-art2.pdf .

COMMISSION OF THE EUROPEAN COMMUNITY. 2000. Communication from the commission to the council and the European Parliament. Indicators for the Integration of 
Environmental Concerns into the Common Agricultural Policy. Brussels, 26.01.2000.

DA CUNHA D. 1988. Towards a Sustainable Housing Development, Open House International, Vol. 13, No. 3, p15p22.

EUROPEAN ENVIRONMENT AGENCY. 1996. CORINAIR 90 Emissions Data. European Topic Centre on Air Emissions.

GALLOPÍN G. 1997. Indicators and their use: information for decision making. In Moldan, B. And Billharz, S. (EDS), Sustainability Indicators. Report on the project on Indicators of Sustainable Development, John Wiley and Sons, Chichester.

GILBERT A. J. AND FEENSTRA JF. 1992. An Indicator of Sustainable Development - Diffusion of Cadmium, Institute for Environmental Studies, VU University Press, Amsterdam.

GOODLAND R. and DALY H. 1996. Environmental sustainability: universal and non-negotiable. Ecological Applications, Vol. 6, No. 4, pp. 1002-1017.

HART M. 1999. Guide to Sustainable Community Indicators, North Andover, Mass.: Hart Environmental Date.

HEALEY P. and SHAW T. 1993. "Planners, Plans and Sustainable development", Regional Studies, Vol.27, No. 8, pp. 769-776.

HOSKARA E. 2007. A Strategic Management Model For Appropriate Sustainable Construction for National Conditions. Unpublsihed PhD Thesis. Instititute of Science. Istanbul Technical University, ?stanbul.

IUCN, 1980. The World Conservation Strategy: Living Resource Conservation for Sustainable Development. International Union for Conservation of Nature (IUCN), Gland, Switzerland.

JACOBS. M.1999. "Sustainable development as a contested concept", in Dobson A. (ed.) (1999) Fairness and Futurity, New York, Oxford University Press, pp. 21-45.

KASL S. 1979. The effect of residential environment on health and behaviour: a review. HINKLE LE. and LORING W., (eds.) The Effect of Man-made Environment on Health and Behaviour, DHEW, 1979, Atlanta, Georgia, pp. 65-128.

KHAN M.A. 1995. Sustainable development: the key concepts, issues and implications. Sustainable Development, Vol. 3, pp. $63-69$.

MACLAREN, CV. 1996. Developing Indicators of Urban Sustainability: A Focus on The Canadian Experience. Toronto, ICURR Press.

MITCHELL, G. 1996. Problems and Fundamentals of Sustainable Development Indicators. Sustainable Development $4,1: 1$.

MITCHELL, G. MAY, A. and McDONALD, A. 1995. PICABUE: A Methodological Framework for the Development of Indicators of Sustainable Development. International Journal of Sustainable Development and World Ecology, 2, 104-123.

MITLIN, D and SATTERTHWAITE, D. 1996. In Pugh, C. (Ed.), Sustainable Development and Cities, pp. 23-62.

MOSER C. 1987. Introduction. in, Moser C. and Peake L. (eds.). Women, Human Settlements and Housing, Tavistock Publications, London.

MORTENSEN L F. 1997. The Driving Force-State-Response framework used by the CSD. In: MOLDAN B., BILLHARZ S. and MATRAVERS R. (eds.): Sustainability Indicators: A Report on the Project on Indicators of Sustainable Development, pp. 4753. New York: John Wiley and Sons.

OECD. 1997. Better Understanding Our Cities, The Role of Urban Indicators. Rennes, Organisation for Economic CoOperation and Development (OECD): 96.

OECD 1993. OECD Core set of indicators for environmental performance reviews. A synthesis report by the group on the state of the environment, OECD, Paris.

OKTAY B. 2005. A Model for Measuring the Level of Sustainability of Historic Urban quarters: Comparative Case Studies of Kyrenia and Famagusta in North Cyprus. Unpublished PhD Thesis. Eastern Mediterranean University, Famagusta, North Cyprus.

PLANNING AUTHORITY, 1997. Sustainability Indicators for Malta - A Proposal. Final Draft Report. pp:36, Floriana: Planning Authority.

RANDALL S. (available in 2004). The Sustainable Development of Oxford City. Online. Available:

//www.brookes.ac.uk/schools/rem/dissertations/2000/sarah_ra ndal.html.

RASMUSSEN S. and DALSGAARD MT. 1994. Systemanalyse \& systemsprog - manual til beskrivelse og analyse af landbrugsbedriften. Notat, Sektion for Økonomi, KVL. pp -48.

SUSTAINABLE SEATTLE. 1995. A Report to the President's Council on Sustainable Development, a joint project by the Center for Sustainable Communities, Sustainable Seattle, and AtKisson \& Associates, Inc., Seattle, Washington, 1995.

UNITED NATIONS SUSTAINABLE DEVELOPMENT. 1992.

Agenda 21, Chapter 7, Online. Available:

habitat.igc.org/agenda21/a21-07.htm

UNCDS.1996. Indicators of Sustainable Development Framework and Methodologies. New York.

UNCHS, 1996. Habitat Agenda. United Nations Organization, Conference on Human Settlements (Habitat II), Istanbul. http://www.unhabitat.org/declarations/habitat_agenda.asp.

VEMURI V. 1978. Modelling of Complex Systems - An Introduction, New York: Academic Press.

WILLIAMS K., BURTON E. and JENKS M. (eds.). 2000. Achieving Sustainable Urban Form, London; New York: E\& FN Spon.

WORLD BANK. 1999. World Development Indicators. The World Bank.

WORLD COMMISSION ON ENVIRONMENT AND DEVELOPMENT. 1987. Our Common Future, Oxford University press, Brundtland Report.

Web sites:

http://www.housingcorp.gov.uk/server/show/nav. 1408

\section{Authors' Address:}

Eastern Mediterranean University

Faculty of Architecture

Famagusta, North Cyprus

Mersin 10, Turkey

beser.oktay@emu.edu.tr

ercan.hoskara@emu.edu.tr

sebnem.onal@emu.edu.tr 
Reproduced with permission of the copyright owner. Further reproduction prohibited without permission. 